\title{
Melatonin and alpha lipoic acid restore electrolytes and kidney morphology of lopinavir/ritonavir-treated rats
}

\author{
Elias Adikwu ${ }^{(\mathbb{D}}$, Nelson Brambaifa, Wolfe Atuboyedia Obianime \\ Department of Pharmacology, Faculty of Basic Medical Sciences, University of Port Harcourt, Port Harcourt, Rivers State, Nigeria
}

\section{A R T I C L E I N F O}

Article Type:

Original

\section{Article History:}

Received: 19 January 2019

Accepted: 28 April 2019

Published online: 23 August 2019

\section{Keywords:}

Lopinavir/ritonavir

Kidney

Toxicity

Antioxidants

Protection

Oxidative stress

\begin{abstract}
A B S T R A C T
Introduction: Lopinavir/ritonavir (LPV/r) may cause renal dysfunction such as electrolyte and acid base disorders and alteration in kidney morphology. Drug-induced renal dysfunction can occur through multiple mechanisms including oxidative stress and inflammation.

Objectives: The current study aimed at evaluating the protective effects of melatonin (MT) and alpha lipoic acid (ALA) against serum electrolytes and kidney histology of LPV/r-treated rats. Adult albino rats were randomized into six groups (A to F). Rats in the control groups were treated orally with normal saline and $1 \%$ ethanol as placebo and solvent control for 90 days respectively. Rats in the experimental groups were pre-treated orally with $10 \mathrm{mg} / \mathrm{kg}$ of MT, 10 $\mathrm{mg} / \mathrm{kg}$ of ALA, and MT+ ALA daily before treatment with 22.9/5.71, 45.6/11.4 94 and 91.4/22.9 $\mathrm{mg} / \mathrm{kg} / \mathrm{d}$ of LPV/r for 90 days respectively.

Materials and Methods: At the end of treatment, rats were euthanized. Blood samples were collected and serum samples were extracted and evaluated for electrolytes, total protein, and albumin. Additionally, kidneys were excised via dissection and evaluated for morphological changes.

Results: Significant $(P<0.001)$ decreases in serum sodium, potassium, chloride, bicarbonate, total protein and albumin in a dose-dependent fashion were obtained in LPV/r-treated rats when compared to control. Dose-dependent kidney morphological changes characterised by tubular necroses were obtained in LPV/r-treated rats. The observations in LPV/r-treated rats were significantly reversed in MT $(P<0.01)$, ALA $(P<0.01)$ and MT+ALA $(P<0.001)$ pre-treated rats when compared to $\mathrm{LPV} / \mathrm{r}$-treated rats.

Conclusion: MT and ALA can serve as adjuvant therapies for LPV/r-associated alterations in serum electrolytes and kidney histology.
\end{abstract}

\footnotetext{
Implication for health policy/practice/research/medical education:

This study discovered that melatonin and alpha lipoic acid may have clinical applications as adjunct therapies for lopinavir/ritonavir associated alterations in serum electrolytes and kidney morphology.

Please cite this paper as: Adikwu E, Brambaifa N, Obianime WA. Melatonin and alpha lipoic acid restore electrolytes and kidney morphology of lopinavir/ritonavir-treated rats. J Nephropharmacol. 2020;9(1):e06. DOI: 10.15171/npj.2020.06.
}

\section{Introduction}

The use of lopinavir/ritonavir (LPV/r) as an essential component of highly active antiretroviral therapy (HAART) has improved the prognosis of human immunodeficiency virus (HIV)-infected people. It has reduced the risk of early death from opportunistic infections and other consequences that could arise as a result of HIV infection. Nonetheless, LPV/r use could be characterized by some adverse consequences like renal dysfunction which may have higher risk than its therapeutic benefit (1). Clinically, HAART can precipitate various forms of renal dysfunctions including electrolyte and acid base disorders, acute kidney injury, lactic acidosis, and chronic kidney disease (2). Additionally, acute tubular necrosis, interstitial infiltrates, fibrosis, and edema, with cytopathic changes involving proximal and distal tubules are some evident features of HAART associated renal pathology (3). The aforementioned kidney injuries can occur through multiple mechanisms, including oxidative stress, inflammation, direct tubular toxicity, and allergic reactions (4). Oxidative stress through free radical production leading to lipid, DNA, and protein damage with the activation of apoptotic pathways, and the initiation of inflammatory response has been implicated in drug- induced kidney injury (5).

Melatonin (MT) is a natural neurotransmitter-like 
compound produced by the pineal gland. It is involved in the biologic and physiologic regulations of body functions. MT is an important antioxidant and also a wide spectrum anti-inflammatory molecule, that modulates both pro- and anti-inflammatory cytokines in different pathophysiologic conditions (6). It acts as a universal, multifunctional and chain breaking antioxidant through direct free radical scavenging, and the stimulation of antioxidative enzymes. It also increases the effectiveness of mitochondrial oxidative phosphorylation and diminishes electron leakage (thus reducing free radical generation) (7). MT and its metabolites can produce synergistic reaction cascade against reactive oxygen species (ROS) and reactive nitrogen species (RNS). This amplifies its efficacy and expands its spectrum of action against oxidative and nitrosative stress (8). Its high lipophilicity and hydrophilicity enables it to offer both intracellular and extracellular antioxidant activity in cells (9). In addition, it has shown potential health benefits in diseases such as cancer, hypertension, diabetes and obesity (9).

Alpha-lipoic acid (ALA), also known as thioctic acid is an essential cofactor in mitochondrial dehydrogenase reactions. It is soluble in water and lipid, and is widely distributed in cellular membrane, cytosol, and extracellular space (10). It acts as a redox regulator of thiol-containing proteins with anti-inflammatory and immunomodulatory activities and has potential for the treatment of some disease conditions (11). The anti-inflammatory effect of ALA includes inhibition of pro-inflammatory cytokines and the stimulation of anti-inflammatory cytokines (12). The redox activity of ALA and its reduced form dihydrolipoic acid (DHLA) is characterized by direct scavenging of free radicals, both in-vitro and in-vivo and the regeneration of other essential antioxidant molecules such as coenzyme Q10, vitamin C and vitamin E. In addition, ALA/ DHLA can prevent proteins, lipids, and DNA from damage caused by oxidative stress (13).

\section{Objectives}

The current study aimed at evaluating the protective effects of MT and ALA against a rat model of LPV/rinduced alterations in serum electrolytes and kidney histology.

\section{Materials and Methods \\ Animal care}

Eighty-five adult albino rats were sourced from the animal house of the Department of Pharmacology, University of Port Harcourt, Rivers State, Nigeria. The albino rats were adapted to laboratory conditions one week prior to the beginning of the experiment. The albino rats were maintained at standard temperature $\left(22-24^{\circ} \mathrm{C}\right)$ and a period of $12 \mathrm{hr}$ light, and $12 \mathrm{hr}$ darkness. The albino rats had free access to food and water ad libitum. The albino rats were randomised into six groups A to F. Group A (Control) contained 10 albino rats which were sub-divided into two groups' A1 (placebo control) and A2 (solvent control) of 5 albino rats each. Groups B-F contained 15 albino rats each which were sub-divided into three groups of 5 albino rats each.

\section{Drugs and chemicals}

MT and ALA were supplied by AO Pharm Import and Export Co Ltd China whereas LPV/r was manufactured by Myland Laboratories Limited India. The doses of $\mathrm{LPV} / \mathrm{r}$ which represent 2,4 and 8 times the clinical dose (14), $10 \mathrm{mg} / \mathrm{kg}$ of MT and $10 \mathrm{mg} / \mathrm{kg}$ of ALA were used for this study $(15,16)$. Water was used as the solvent for ALA (17), whereas $1 \%$ ethanol was used as the solvent for $\mathrm{LPV} / \mathrm{r}$ (18). MT was dissolve in $1 \%$ ethanol and diluted with normal saline (19).

\section{Drug administration}

Rats in group A1 (placebo control) and group A2 (solvent control) were treated orally with $0.2 \mathrm{~mL}$ of normal saline and $1 \%$ ethanol for 90 days respectively. Rats in group B were treated orally with 22.9/5.71, 45.6/11.4 94 and $91.4 / 22.9 \mathrm{mg} / \mathrm{kg} / \mathrm{d}$ of $\mathrm{LPV} / \mathrm{r}$ for 90 days respectively. Rats in group C were treated orally with $10 \mathrm{mg} / \mathrm{kg}$ of MT, $10 \mathrm{mg} /$ $\mathrm{kg}$ of ALA, and MT +ALA daily for 90 days respectively. Rats in groups D- F were pre-treated orally with $10 \mathrm{mg} /$ $\mathrm{kg}$ of MT, $10 \mathrm{mg} / \mathrm{kg}$ of ALA, and MT+ALA daily prior to treatment with 22.9/5.71, $345.6 / 11.4$ and $91.4 / 22.9 \mathrm{mg} /$ $\mathrm{kg} / \mathrm{d}$ of LPV/r for 90 days respectively.

\section{Animal sacrifice, sample collection and evaluation}

At the end of treatment, albino rats were fasted overnight and sacrificed with the aid of diethyl ether and blood samples were collected in plain bottles. The blood samples were allowed to clot and retract after which serum samples were isolated after centrifugation at $2000 \mathrm{~g}$ for 15 minutes. Serum samples were analysed for potassium $\left(\mathrm{K}^{+}\right)$, sodium $\left(\mathrm{Na}^{+}\right)$, bicarbonate $\left(\mathrm{HCO}_{3}^{-}\right)$, and chloride $\left(\mathrm{Cl}^{-}\right)$, albumin and total protein using standard laboratory reagents. The albino rats were dissected kidney tissues were collected, cleaned, processed using standard laboratory technique and stained with hematoxylin and eosin ( $\mathrm{H} \& \mathrm{E})$. Prepared kidney tissues were examined for pathology with the aid of a microscope.

\section{Statistical analysis}

Differences between groups were compared using one way analysis of variance (ANOVA) followed by Dunnett's post hoc test using. Data was statistically analyzed using SPSS/17.0 software. Differences were considered significant at $<0.01$ and $<0.001$.

\section{Ethical issues}

The research was approved by the Research Ethics Committee of the University of Port Harcourt, Nigeria. Prior to the experiment, the protocols were confirmed to be in accordance with the guidelines of Animal Ethics 
Table 1. Effects of melatonin and alpha lipoic acid on serum electrolytes, total protein and albumin of albino rats

\begin{tabular}{llcccc}
\hline Group & $\mathrm{K}^{+}(\mathrm{mmol} / \mathrm{L})$ & $\mathrm{Na}^{+}(\mathrm{mmol} / \mathrm{L})$ & $\mathrm{Cl}^{-}(\mathrm{mmol} / \mathrm{L})$ & $\mathrm{HCO}_{3}^{-}(\mathrm{mmol} / \mathrm{L})$ & Total $\mathrm{protein}(\mathrm{g} / \mathrm{dL})$ \\
\hline Control (Placebo) & $2.66 \pm 0.56$ & $110.1 \pm 9.63$ & $106.1 \pm 8.66$ & $10.9 \pm 0.33$ & $4.50 \pm 0.71$ \\
MT & $2.75 \pm 0.27$ & $119.7 \pm 7.43$ & $108.6 \pm 8.70$ & $11.2 \pm 0.25$ & $4.65 \pm 0.26$ \\
ALA & $2.70 \pm 0.38$ & $116.0 \pm 9.57$ & $106.9 \pm 9.50$ & $11.0 \pm 0.77$ & $4.60 \pm 0.32$ \\
MT+ALA & $2.80 \pm 0.76$ & $128.7 \pm 8.16$ & $119.4 \pm 7.95$ & $11.6 \pm 0.32$ & $4.69 \pm 0.57$ \\
\hline
\end{tabular}

Data expressed as Mean \pm SEM, $n=5, M T$; melatonin, $\mathrm{ALA}$; alpha lipoic acid, $\mathrm{K}$; potassium, $\mathrm{HCO}_{3}^{-}$; bicarbonate.

Committee of University of Port Harcourt, Nigeria.

Results

Serum $\mathrm{Na}^{+}, \mathrm{K}^{+}, \mathrm{Cl}^{-}$and $\mathrm{HCO}_{3}^{-}$levels were normal $(P>0.05)$ in rats treated with MT, ALA and MT+ALA when compared to control (Table 1).On the other hand, serum $\mathrm{Na}^{+}, \mathrm{K}^{+}, \mathrm{Cl}^{-}$and $\mathrm{HCO}_{3}^{-}$were significantly $(P<0.001)$ decreased in a dose-dependent fashion in rats treated with $\mathrm{LPV} / \mathrm{r}$ when compared to control (Tables 2 and 3). However, the serum levels of the aforementioned parameters were significantly restored in rats pre-treated with MT $(P<0.01)$ and ALA $(P<0.01)$ when compared to $\mathrm{LPV} / \mathrm{r}$-treated rats. Interestingly pre-treatment with MT+ALA significantly restored the serum levels of $\mathrm{Na}^{+}, \mathrm{K}^{+}, \mathrm{Cl}^{-}$and $\mathrm{HCO}_{3}^{-}$at $P<0.001$ when compared to $\mathrm{LPV} / \mathrm{r}$-treated rats (Tables 2 and 3). The serum levels of total protein and albumin were normal $(P>0.05)$ in rats treated with MT, ALA and MT+ALA when compared to control (Table 1). However, in a dose- dependent fashion, significant $(P<0.001)$ low serum levels of total protein and albumin were obtained in rats treated with $\mathrm{LPV} / \mathrm{r}$ when compared to control (Table 4). On the other hand, serum total protein and albumin levels were significantly restored in MT $(P<0.01)$, ALA $(P<0.01)$ and MT+ALA $(P<0.001)$ pre-treated rats when compared to $\mathrm{LPV} / \mathrm{r}$ treated rats (Table 4). Furthermore, the examined sections of the kidneys of rats treated with MT, ALA and MT+ALA showed normal histology when compared to control (Figures A to D). However, the kidneys of rats treated with LPV/r showed pathology characterised by tubular necroses (Figure E). The kidneys of rats pre-treated with individual doses of MT and ALA showed tubular necroses

Table 2. Effects of melatonin and alpha lipoic acid on serum potassium and bicarbonate of lopinavir/ritonavir-treated albino rats

\begin{tabular}{|c|c|c|c|c|c|}
\hline Dose (mg/kg) & Control & $\mathrm{LPV} / \mathrm{r}$ & MT & ALA & $\mathrm{MT}+\mathrm{ALA}$ \\
\hline \multicolumn{6}{|c|}{ Serum K + (mmol/L) } \\
\hline $22.8 / 5.71$ & $2.66 \pm 0.56$ & $2.00 \pm 0.63 *$ & $2.50 \pm 0.53^{* *}$ & $2.47 \pm 0.44 * *$ & $2.61 \pm 0.44^{* *}$ \\
\hline $45.6 / 11.4$ & $2.66 \pm 0.56$ & $1.55 \pm 0.57 *$ & $2.07 \pm 0.91 * *$ & $2.00 \pm 0.67 * *$ & $2.58 \pm 0.67 * * *$ \\
\hline $91.2 / 22.9$ & $2.66 \pm 0.56$ & $1.00 \pm 0.06 *$ & $1.56 \pm 0.24^{* *}$ & $1.40 \pm 0.09 * *$ & $2.40 \pm 0.11 * * *$ \\
\hline \multicolumn{6}{|c|}{ Serum HCO3-(mmol/L) } \\
\hline $22.8 / 5.71$ & $10.9 \pm 0.33$ & $5.53 \pm 0.60 *$ & $7.67 \pm 0.33^{* *}$ & $7.60 \pm 0.25 * *$ & $10.0 \pm 0.57^{* * *}$ \\
\hline $45.6 / 11.4$ & $10.9 \pm 0.33$ & $3.07 \pm 0.45^{*}$ & $5.50 \pm 0.51^{* *}$ & $5.31 \pm 0.11 * *$ & $8.94 \pm 0.23 * * *$ \\
\hline $91.2 / 22.9$ & $10.9 \pm 0.33$ & $2.05 \pm 0.53^{*}$ & $3.90 \pm 0.22 * *$ & $3.85 \pm 0.31 * *$ & $7.83 \pm 0.17^{* * *}$ \\
\hline
\end{tabular}

Data expressed as Mean $\pm \mathrm{SEM}, \mathrm{n}=5, \mathrm{MT}=$ melatonin, $\mathrm{ALA}$; alpha lipoic Acid, $\mathrm{K}$; potassium, $\mathrm{HCO}_{3}^{-}$; bicarbonate, $\mathrm{Cl}^{-}$; chloride, $\mathrm{Na}^{+}$; sodium.

* Significant $(P<0.001)$ difference when compared to control.

** Significant $(P<0.01)$ difference when compared to LPV/r.

$* * *$ Significant $(P<0.001)$ difference when compared to $\mathrm{LPV} / \mathrm{r}$.

Table 3. Effects of melatonin and alpha lipoic acid on serum chloride and sodium of lopinavir/ritonavir-treated albino rats

\begin{tabular}{|c|c|c|c|c|c|}
\hline Dose (mg/kg) & Control & $\mathrm{LPV} / \mathrm{r}$ & MT & ALA & $M T+A L A$ \\
\hline \multicolumn{6}{|c|}{ Serum $\mathrm{Cl}^{-}(\mathrm{mmol} / \mathrm{L})$} \\
\hline $22.8 / 5.71$ & $106.1 \pm 8.66$ & $60.5 \pm 5.03$ & $88.8 \pm 6.67 * *$ & $80.5 \pm 6.53 * *$ & $100.4 \pm 8.41^{* *}$ \\
\hline $45.6 / 11.4$ & $106.1 \pm 8.66$ & $51.0 \pm 4.57$ & $73.0 \pm 5.71 * *$ & $70.7 \pm 4.32 * *$ & $95.2 \pm 6.65 * * *$ \\
\hline $91.2 / 22.9$ & $106.1 \pm 8.66$ & $40.2 \pm 2.16$ & $61.6 \pm 3.62 * *$ & $58.1 \pm 3.47 * *$ & $91.1 \pm 7.47 * * *$ \\
\hline \multicolumn{6}{|c|}{ Serum $\mathrm{Na}^{+}(\mathrm{mmol} / \mathrm{L})$} \\
\hline $22.8 / 5.71$ & $110.5 \pm 9.63$ & $63.3 \pm 6.63^{*}$ & $83.6 \pm 6.27^{* *}$ & $82.3 \pm 6.31 * *$ & $100.1 \pm 9.10 * *$ \\
\hline $45.6 / 11.4$ & $110.5 \pm 9.63$ & $44.2 \pm 3.57^{*}$ & $68.9 \pm 7.13^{* *}$ & $65.9 \pm 4.51^{* *}$ & $97.4 \pm 7.32 * * *$ \\
\hline $91.2 / 22.9$ & $110.5 \pm 9.63$ & $36.0 \pm 2.16^{*}$ & $63.0 \pm 6.27 * *$ & $59.4 \pm 3.71 * *$ & $90.0 \pm 8.57 * * *$ \\
\hline
\end{tabular}

Data expressed as mean $\pm \mathrm{SEM}, \mathrm{n}=5, \mathrm{MT}$; melatonin, $\mathrm{ALA}$; alpha lipoic acid, $\mathrm{Cl}^{-}$; chloride, $\mathrm{Na}^{+}$; sodium.

* Significant $(P<0.001)$ difference when compared to control.

** Significant $(P<0.01)$ difference when compared to LPV/r.

$* * *$ Significant $(P<0.001)$ difference when compared to $L P V / r$. 
Table 4. Effects of melatonin and alpha lipoic acid on serum total protein and albumin of lopinavir/ritonavir-treated albino rats

\begin{tabular}{llllll}
\hline Dose $(\mathrm{mg} / \mathrm{kg})$ & Control & \multicolumn{1}{l}{ LPV/r } & MT & ALA & MT + ALA \\
\hline \multicolumn{7}{c}{ Serum Total Protein (g/dL) } \\
\hline $22.8 / 5.71$ & $4.50 \pm 0.71$ & $2.00 \pm 0.44^{*}$ & $3.33 \pm 0.33^{* *}$ & $3.21 \pm 0.20^{* *}$ & $4.22 \pm 0.63^{* * *}$ \\
$45.6 / 11.4$ & $4.50 \pm 0.71$ & $1.52 \pm 0.01^{*}$ & $2.07 \pm 0.51^{* *}$ & $2.00 \pm 0.32^{* *}$ & $4.10 \pm 0.41^{* * *}$ \\
$91.2 / 22.9$ & $4.50 \pm 0.71$ & $1.17 \pm 0.08^{*}$ & $1.75 \pm 0.22^{* *}$ & $1.60 \pm 0.01^{* *}$ & $4.00 \pm 0.32^{* * *}$ \\
\hline \multicolumn{7}{c}{ Serum Albumin (g/dL) } \\
\hline $22.8 / 5.71$ & $2.88 \pm 0.23$ & $2.10 \pm 0.63^{*}$ & $2.66 \pm 0.53^{* *}$ & $2.40 \pm 0.32^{* *}$ & $2.70 \pm 0.34^{* *}$ \\
$45.6 / 11.4$ & $2.88 \pm 0.23$ & $1.62 \pm 0.07^{*}$ & $2.09 \pm 0.91^{* *}$ & $2.00 \pm 0.75^{* *}$ & $2.66 \pm 0.24^{* * *}$ \\
$91.2 / 22.9$ & $2.88 \pm 0.23$ & $1.00 \pm 0.06^{*}$ & $1.52 \pm 0.04^{* *}$ & $1.41 \pm 0.03^{* *}$ & $2.57 \pm 0.55^{* * *}$ \\
\hline
\end{tabular}

Data expressed as mean \pm SEM, $n=5, M T$; melatonin, ALA; alpha lipoic acid.

* Significant $(p<0.001)$ difference when compared to control.

** Significant $(p<0.01)$ difference when compared to LPV/r.

*** Significant $(p<0.001)$ difference when compared to LPV/r.

respectively (Figures F and G). However, the kidney of rat pre-treated with MT+ ALA showed normal histology (Figure $\mathrm{H}$ ).

\section{Discussion}

Kidney plays a major role in the metabolism and excretion of waste products of metabolism including drug metabolites (20). However, the physiological functions of the kidney can be impaired due to its vulnerability to various forms of toxic insults (21). Kidney injury ranging from electrolyte dysfunction to evident pathology in the structure of kidney can arise from the use of LPV/r (22). Renal pathology associated with xenobiotics can occur through different mechanisms including oxidative stress and inflammation. MT and ALA have antioxidant and anti-inflammatory effects therefore, the current study examined the protective effects of MT and ALA against a rat model of LPV/r-induced alterations in serum electrolytes and kidney histology. Electrolytes which include $\mathrm{Na}^{+}, \mathrm{K}$, $\mathrm{Cl}^{-}$and $\mathrm{HCO}_{3}{ }^{-}$are charged low molecular mass molecules present in plasma and cytosol. Electrolytes have essential functions which include water balance, maintenance of $\mathrm{pH}$, regulation of heart and muscle function, electron transfer reactions as well as serving as cofactors for enzymes. Specifically, $\mathrm{Na}^{+}$is the major extracellular cation that maintains the normal distribution of water and osmotic pressure in various fluid compartments (23). Serum $\mathrm{K}^{-}$is the major intracellular cation that regulates heartbeat and the functions of the muscles in addition to other functions (23). On the other hand, $\mathrm{Cl}^{-}$ in conjunction with $\mathrm{Na}^{+}$are involved in the maintenance of water distribution, osmotic pressure and anion-cation balance in extracellular fluid. Studies have shown that the evaluations of body fluid concentrations of $\mathrm{Na}^{+}, \mathrm{K}^{+}, \mathrm{Cl}^{-}$ and $\mathrm{HCO}_{3}^{-}$are clinically used as electrolyte profile in the assessment of kidney disorder (24). In the current study, normal serum $\mathrm{Na}^{+}, \mathrm{K}^{+}, \mathrm{Cl}^{-}$and $\mathrm{HCO}_{3}^{-}$levels were observed in rats treated with MT, ALA and MT+ALA. On the other hand, the above serum electrolytes were decreased in a dose-dependent fashion in rats treated with LPV/r.

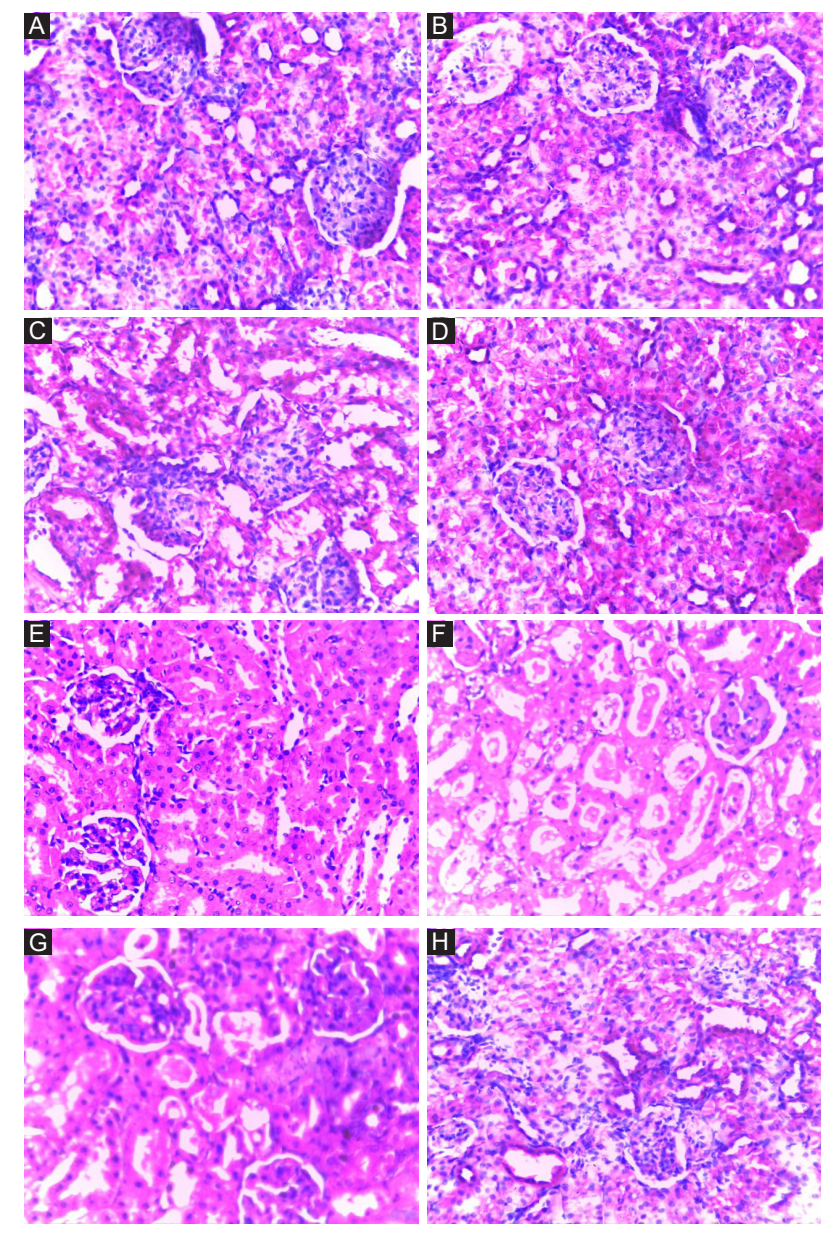

Figure 1. A: Kidney of control rat showing normal tubules. B: Kidney of rat treated with $10 \mathrm{mg} / \mathrm{kg} / \mathrm{d}$ of melatonin (MT) showing normal tubules. C: Kidney of rat treated with $10 \mathrm{mg} / \mathrm{kg} / \mathrm{d}$ of alpha lipoic acid (ALA) showing normal tubules. D: Kidney of rat treated with a combination of MT and ALA showing normal tubules. E: Kidney of rat treated with $45.6 / 11.4 \mathrm{mg} / \mathrm{kg} / \mathrm{d}$ of lopinavir/ritonavir showing tubular necrosis. F: Kidney of rat treated with $10 \mathrm{mg} / \mathrm{kg} / \mathrm{d}$ of MT and 45.6/11.4 $\mathrm{mg} / \mathrm{kg} / \mathrm{d}$ of lopinavir/ritonavir showing tubular necrosis. $\mathbf{H}$ : Kidney of rat treated with $10 \mathrm{mg} / \mathrm{kg} / \mathrm{d}$ of ALA and $45.6 / 11.4 \mathrm{mg} / \mathrm{kg} / \mathrm{d}$ of lopinavir/ ritonavir showing tubular necrosis. G: Kidney of rat treated with 10 $\mathrm{mg} / \mathrm{kg} / \mathrm{d}$ of ALA and $10 \mathrm{mg} / \mathrm{kg} / \mathrm{d}$ of MT and $45.6 / 11.4 \mathrm{mg} / \mathrm{kg} / \mathrm{d}$ of lopinavir/ritonavir showing normal tubules $(\mathrm{H} \& \mathrm{E}) \times 400$. 
However, the serum levels of $\mathrm{Na}^{+}, \mathrm{K}^{+}, \mathrm{Cl}^{-}$and $\mathrm{HCO}_{3}^{-}$were restored in rats pre-treated with individual doses of $\mathrm{MT}$ and ALA. Interestingly, most restored levels of $\mathrm{Na}^{+}, \mathrm{K}^{+}, \mathrm{Cl}^{-}$ and $\mathrm{HCO}_{3}{ }^{-}$occurred in MT+ALA pre-treated rats. Studies have shown that increased renal disposal of protein often characterise chronic kidney disease and is an established predictor of chronic kidney disease progression that reflects both glomerular and tubulointerstitial injury (25). This study observed normal serum levels of total protein and albumin in rats treated with MT, ALA and MT+ ALA. However, in a dose-dependent fashion, serum levels of total protein and albumin were decreased in rats treated with LPV/r. This observation is a sign of renal dysfunction that has been previously reported (26). On the other hand, the serum levels of the aforementioned parameters were restored in rats pre-treated with individual dose of MT, and ALA with most restored levels observed in MT+ ALA pre-treated rats. Furthermore, the examined sections of the kidneys of rats treated with MT, ALA and MT+ ALA showed normal histology. In contrast, the kidneys of rats treated with LPV/r showed pathology characterised by tubular necroses. The observation in LPV/r-treated rats is in agreement with earlier reports (27). Interestingly, this study observed decreased tubular necroses in the kidneys of rats pre-treated with individual doses of MT and ALA. On the other hand, tubular necrosis was completely abrogated in rat pre-treated with MT+ALA.

Therapy with LPV/r can produce electrolytes and acid-base derangements with progressive loss of kidney function. Electrolytes and acid-base alterations form a major part of the pathological disease processes associated with renal failure (28). In the current study, the mechanisms by which LPV/r caused alterations in serum electrolytes and kidney histology are not well understood. However, studies have shown that drug-induced renal dysfunction could be associated with the following mechanisms; altered intra-glomerular hemodynamics, tubular cell toxicity, oxidative stress, inflammation, crystal nephropathy, rhabdomyolysis, and thrombotic microangiopathy (29). Recently, the place of oxidative stress in drug-induced renal dysfunction has gained so much attention. This has been attributed to drug or metabolite-induced free radical production which can stimulate biomolecular damage in the kidney through the initiation of LPO, inflammation and the stimulation of apoptotic pathways (30). Oxidative stress could be one of the primary mechanisms by which LPV/r causes renal dysfunction because it has been associated with free radical generation and the perturbation of kidney antioxidant defense (31). The protective effects of MT and ALA observed in this study may be due to their inhibitory effects on the oxidative and inflammatory actions of LPV/ $\mathrm{r}$ in the kidneys of treated rats. MT is a multifunctional, universal and chain breaking antioxidant that forms reaction cascade against oxidants. Furthermore, it regulates a number of inflammatory reactions by up-regulating anti-inflammatory and inhibiting pro-inflammatory cytokines (32). ALA is a thiol containing antioxidant that terminates oxidative and nitrosative stress by scavenging and neutralizing ROS and RNS. Besides, it is an anti-inflammatory agent that inhibits processes associated with the production of mediators of inflammation in-vitro and in-vivo (33). In this study, the nephroprotective effect observed with the concurrent use of MT and ALA could be attributed to their stimulatory effects on each other.

\section{Conclusion}

MT and ALA can serve as adjuvant therapies for LPV/r associated alterations in serum electrolytes and kidney morphology.

\section{Authors' contribution}

EA; Study design, literature search, animal handling and treatment, data collection, data analysis, manuscript preparation and revision. BN; Study design, literature search, literature review, manuscript editing, manuscript preparation and revision. WAO; Study design, literature search, literature review, manuscript editing, manuscript preparation and revision.

\section{Conflicts of interest}

The authors declared no competing interests.

Ethical considerations

Ethical issues (including plagiarism, misconduct, data fabrication, falsification, double publication or submission, redundancy) have been completely observed by the authors.

\section{Funding/Support}

None.

\section{References}

1. Ngala RA, Opoku D, Asare G. Effects of HIV Infection and Highly Active Antiretroviral Therapy (HAART) on the Liver of HIV Patients. Trends in Med Res. 2015;10(1):1-11. doi: 10.3923/tmr.2015.1.11

2. Izzedine $H$, Harris $M$, Perazella MA, The nephrotoxic effects of HAART. Nat Rev Nephrol. 2009;5:563-73.

3. Berns SF, Kasbekar N. Highly active antiretroviral therapy and the kidney: an update on antiretroviral medications for nephrologist. Clin J Am Soc Nephrol. 2006;1:117-129.

4. Wyatt CM, Morgello S, Katz-Malamed R. The spectrum of kidney disease in patients with AIDS in the era of antiretroviral therapy. Kidney Int. 2009;75:428-434.

5. Miller RP, Tadagavadi RK, Ramesh G, Reeves WB. Mechanisms of Cisplatin Nephrotoxicity. Toxins. 2010;2:2490-518.

6. Favero G, Franceschetti L, Bonomini F, Rodella FL, Rezzani R. Melatonin as an anti-inflammatory agent modulating inflammasome activation. Intern J Endocrin. 2017;2017:1835195. 
7. Reiter RJ, Tan D, Mayo JC, Sainz RM, Leon J, Czarnocki Z. Melatonin as an antioxidant: biochemical mechanisms and pathophysiological implications in humans. Acta Biochem Polan. 2003; 50:1129-46.

8. Tan DX, Manchester LC. Significance of melatonin in antioxidative defense system: Reactions and products. Biol Signals Recept. 2000;9:137-159.

9. Ronnberg L, Kauppila A, Leppaluoto J, Martikainen H, Vakkuri O. Circadian and seasonal variation in human preovulatory follicular fluid melatonin concentration. J Clin Endocrinol Metab 1990;71:492-6.

10. Packer L, Witt EH. Tritschler HJ. Alpha-lipoic acid as a biological antioxidant. Free Radic Biol Med. 1995; 19;227250 .

11. Parente E, Colannino G, Picconi O, Monastra G. Safety of oral alpha-lipoic acid treatment in pregnant women: a retrospective observational study. Eur Rev Med Pharm Sci. 2017;21:4219-4227.

12. Li G, Fu J, Zhao Y, Ji K, Luan T, Zang B. Alpha-lipoic acid exerts anti-inflammatory effects on lipopolysaccharidestimulated rat mesangial cells via inhibition of nuclear factor kappa B (NF- $\mathrm{b})$ signalling pathway. Inflammation. 2015;38:510-9. doi: 10.1007/s10753-014-9957-3.

13. Petersen Shay K, Moreau RF, Smith EJ, Hagen TM. Is alphalipoic acid a scavenger of reactive oxygen species in vivo? Evidence for its initiation of stress signaling pathways that promote endogenous antioxidant capacity. IUBMB Life. 2008; 60:362-7.

14. Hull MW, Harris M, Lima V, Guillemi S, Harrigan PR, Montaner JS. Lopinavir/ritonavir pharmacokinetics in a substitution of high-dose soft-gelatin capsule to 10 tablet formulation. J Clin Pharm. 2009;49:155-61.

15. Ali WS. Comparative study between marjoram and alpha lipoic acid on potassium bromide induced oxidative stress in rats. World J Dairy Food Sci. 2013;8:94-9.

16. Bilginoğlu A, Aydın D, Özsoy S, Aygün H. Protective effect of melatonin on adriamycin-induced cardiotoxicity in rats. Arch Turk Soc Cardiol. 2014;42:265-73.

17. Shagirtha K, Muthumani M, Prabu S. Melatonin abrogates cadmium induced oxidative stress related neurotoxicity in rats. Eur Rev for Med and Pharm Sci; 2011; 15, 1039-1050.

18. Reyskens KMSE, Fisher TL, Schisler JC, O’Connor WG, Rogers AB. Cardio-Metabolic Effects of HIV Protease Inhibitors (Lopinavir/ Ritonavir), PLoS One. 2013; 8(9): e73347. doi: 10.1371/journal.pone.0073347

19. 19. Kaplan M, Atakan IH, Aydoğdu N, Aktoz T, Puyan, FO, Seren G, et al. The effect of melatonin on cadmiuminduced renal injury in chronically exposed rats. Turk J Urol 2009; 35:139-147.

20. 20. Dixon J, Lane K, MacPhee I, Philips B Xenobiotic
Metabolism: Xenobiotic metabolism: the effect of acute kidney injury on non-renal drug clearance and hepatic drug metabolism. Int J Mol Sci. 2014;15:2538-53. doi: 10.3390/ijms15022538.

21. Izzedine H, Launay-Vacher V, Deray G. Antiviral druginduced nephrotoxicity. Am J Kidney Dis. 2005;45:804817.

22. Kalyesubula R, Perazella MA. Nephrotoxicity of HAART. AIDS Res Treat. 2011;2011:562790.

23. Burtis CA, Bruns DE, Ashwood ER. (2017) Electrolytes. In: Burtis CA, Bruns DE, Ashwood ER, eds. In: Tietz Fundamentals of Clinical Chemistry and Molecular Diagnostics. 8th ed. Elsevier; 2017. doi: $10.1155 / 2011 / 562790$.

24. Cheesbrough M. Measurement of Sodium and Potassium in Serum or Plasma. In: Cheesbrough M (ed.). District Laboratory Practice in Topical Countries, Part 1. Cape Town, South Africa: Cambridge University Press; 2006. 364-369.

25. Tesch GH. Review: Serum and urine biomarkers of kidney disease: A pathophysiological perspective. Nephrology (Carlton). 2010;15:609-16

26. Herman JS, Ives NJ, Nelson M, Gazzard BG. Incidence and risk factors for the development of indinavir-associated renal complications. J Antimicrob Chemoth. 2001;48:355360.

27. Pacanowski J, Poirier JM, Petit I, Meynard JL, Girard PM. Atazanavir urinary stones in an $\mathrm{HIV}$-infected patient. AIDS. 2006;20:2131.

28. Dhondup T, Qian Q. Electrolyte and Acid-Base Disorders in Chronic Kidney Disease and End-Stage Kidney Failure Tsering. Blood Purif 2017;43:179-88. doi: $10.1159 / 000452725$.

29. Naughton CA, Drug-Induced Nephrotoxicity. Am Fam Physician. 2008;78:743-50.

30. Amiri M. Oxidative stress and free radicals in liver and kidney diseases; an updated short-review. J Nephropathol. 2018;7:127-131. doi: 10.15171/jnp.2018.30.

31. Adikwu E, Brambaifa N, Obianime WA. Melatonin and alpha lipoic acid: possible mitigants for lopinavir/ritonavirinduced renal toxicity in male albino rats. Physiol and Pharm. 2016; 19: 232-240.

32. Adikwu E, Bokolo B. Melatonin and N- Acetylcysteine as Remedies for Tramadol-Induced Hepatotoxicity in Albino Rats. Adv Pharm Bull. 2017;7:367-374. doi: 10.15171/ apb.2017.044.

33. Adikwu E, Brambaifa N, Obianime WA. Melatonin and alpha lipoic acid as possible therapies for lopinavir/ ritonavir-induced hepatotoxicity in albino rats. Physiol Pharm. 2016;20:287-295.

Copyright $\odot 2020$ The Author(s); Published by Published by Society of Diabetic Nephropathy Prevention. This is an open-access article distributed under the terms of the Creative Commons Attribution License (http://creativecommons.org/licenses/by/4.0), which permits unrestricted use, distribution, and reproduction in any medium, provided the original work is properly cited. 